\title{
Transfer of Haemophilus vaginalis Gardner and Dukes to a New Genus, Gardnerella: G. vaginalis (Gardner and Dukes) comb. nov.
}

\author{
J. R. GREENWOOD AND M. J. PICKETT \\ Department of Microbiology, University of California, Los Angeles, California 90024
}

\begin{abstract}
A taxonomic study of Haemophilus vaginalis Gardner and Dukes was undertaken to determine relationships between this organism and members of other genera. The methods utilized included Adansonian analysis, deoxyribonucleic acid (DNA)-DNA hybridizations, electron microscopy, and biochemical analysis of cell envelopes. By numerical analysis, all 78 clinical isolates and reference strains examined were related to each other at a similarity level exceeding $95 \%$. No subspecies or biovars were observed. DNA-DNA hybridizations showed no genetic relationship between $\mathrm{H}$. vaginalis and members of the genera Haemophilus, Pasteurella, and Streptococcus. Also, no relationship was observed between $H$. vaginalis and CDC DF-1. In the absence of existing genera with genetic features compatible with $H$. vaginalis, we propose the new genus Gardnerella for inclusion of organisms presently designated as either $H$. vaginalis or Cory. nebacterium vaginale. Gardnerella is defined to include catalase- and oxidasenegative, gram-negative to gram-variable bacteria with laminated cell walls which produce acetic acid as the major end product of fermentation. The type species of Gardnerella is G. vaginalis (Gardner and Dukes) comb. nov. Due to the unusual cell wall of this organism, this new genus is not presently assignable to a family.
\end{abstract}

In 1953, Leopold (19) reported the isolation of a small, pleomorphic, gram-negative, rod-shaped bacterium from men with prostatitis and women with cervicitis. This report suggested that these pleomorphic rods resembled members of the genus Haemophilus. Two years later, Gardner and Dukes (13) reported finding organisms of a similar description associated with cases of "nonspecific" bacterial vaginitis. They named this organism Haemophilus vaginalis and stated that it was, indeed, the etiological agent of bacterial vaginitis. Since the original Gardner and Dukes work, however, numerous contradictory reports have been published regarding not only the pathogenic potential of $H$. vaginalis $(5,12$, $17,27)$ but also its taxonomic status $(2,6,29,36)$.

In obvious conflict with the definition of the genus Haemophilus (2), H. vaginalis was shown not to require hemin ( $\mathrm{X}$ factor), nicotinamide adenine dinucleotide ( $\mathrm{V}$ factor), or any other coenzyme-like growth factor $(10,11)$. Thus, Zinnemann and Turner (37) recommended the removal of $H$. vaginalis from the genus Haemo. philus and its reclassification in the genus $\mathrm{Cor}$ ynebacterium. The suggested name of the organism was Corynebacterium vaginale. Zinnemann and Turner based arguments for inclusion of this organism in Corynebacterium strictly on morphological grounds. They reported that, when grown under "optimal" growth conditions, $H$. vaginalis consistently stained gram positive and formed polar granules, clubs, and "chinese characters." Thus, they felt that $H$. vaginalis had a microscopic morphology resembling that of a corynebacterium.

The first study of $H$. vaginalis by electron microscopy was reported by Reyn et al. (29). These authors concluded that in thin sections of osmium-fixed cells, cell walls and septa of this organism resembled those of gram-positive organisms. However, Criswell et al. $(6,7)$, in later electron microscopy studies of the same strain used by Reyn et al., determined that the fine structure of the cell walls was more consistent with that of a gram-negative organism. Additionally, Criswell et al. (6) examined the biochemical composition of $H$. vaginalis. Their analysis showed the cell walls to have a composition typical of that of a gram-negative organism.

Genera other then Haemophilus and Corynebacterium have also been proposed as appropriate for $H$. vaginalis. These have included Lactobacillus, Eubacterium, Butyribacterium, and Propionibacterium (2). A relationship to members of the genus Actinomyces has also 
been suggested (2). The following study was undertaken because of the taxonomic uncertainty regarding $H$. vaginalis.

\section{MATERIALS AND METHODS}

Bacterial strains. A total of 78 strains of $\mathrm{H}$. vaginalis was examined by numerical taxonomy methods. The organisms used and their sources are shown in Table 1.

Numerical taxonomy. All strains were examined for 104 features. These included biochemical reactions, growth under various environmental conditions, susceptibility to inhibitory agents, and other standard bacteriological tests. The reactions of these strains in these tests have been published elsewhere (14). Each feature was scored as either 0 for a negative reaction or 1 for a positive reaction. As a control of the method, one organism was given a different code number and examined separately. The computer program selected for the numerical analysis was NT-SYS, a program developed at the University of Kansas and later modified at State University of New York, Stony Brook. The unweighted pair-group method with averages (UPGMA) was used with the simple matching coefficient for data analysis.

Lipopolysaccharide extraction. Lipopolysaccharide was prepared by a modified hot phenol-water method (37). H. vaginalis ATCC 14018 was cultivated in 6 to 10 liters of heart infusion broth (Difro Laboratories, Detroit, Mich.) supplemented with \% proteose peptone no. 3 (Difco Laboratories) and 0.5\% maltose. The broth cultures were incubated in air at $35^{\circ} \mathrm{C}$ for $48 \mathrm{~h}$. Cells were sedimented, and approximately $4 \mathrm{~g}$ (wet weight) of cell paste was added to 10 $\mathrm{ml}$ of distilled water. The suspension was adjusted to $\mathrm{pH} 7$ and heated to 65 to $68^{\circ} \mathrm{C}$ on a magnetic-stirring hot plate. An equal volume of liquefied phenol (Mallinckrodt J, Inc., St. Louis, Mo.) was heated to 65 to $68^{\circ} \mathrm{C}$ and added to the cell suspension. The suspension was mixed with a stirring bar for $15 \mathrm{~min}$ at 65 to $68^{\circ} \mathrm{C}$, cooled by transfer to an ice bath, and then centrifuged at $3,000 \times g$ for $30 \mathrm{~min}$. The upper aqueous layer was removed, and the phenol layer was reextracted with an equal volume of water. Both aqueous layers were combined and dialyzed in the cold $\left(4^{\circ} \mathrm{C}\right)$ for 3 days against frequent changes of distilled water. Nucleic acids were removed from this preparation either by repeated centrifugation at $150,000 \times g$ for $3 \mathrm{~h}$ or by ethyl alcohol precipitation in the presence of sodium acetate (37).

Lipopolysaccharide analysis. The periodatethiobarbiturate method (35) was used to assay for the presence of 2-keto-3-deoxyoctonate. Authentic 2-keto3-deoxyoctonate was kindly supplied by S. C. Rittenberg, Department of Microbiology, University of California, Los Angeles. For fatty acid analysis, lipopolysaccharide was hydrolyzed with $\mathrm{HCl}$ and then methylated with $\mathrm{BF}_{3}$-methanol $\left(\mathrm{BF}_{3}\right.$-methanol, $14 \% \mathrm{wt} / \mathrm{vol}$, Analabs, Inc., North Haven, Conn.) (23). The residual esters were dissolved in $n$-hexane, and triplicate samples were injected into a model 5992A gas chromatograph-mass spectrometer (Hewlett Packard, Palo Alto, Calif.). The chromatograph was equipped with a 6 -ft (ca. $1.83 \mathrm{~m}$ ) stainless steel column (6-mm outside diameter, 2-mm inside diameter) packed with $3 \%$ Silar 10c on Gas-Chrom Q 100/120 mesh (Applied Science Laboratories, State College, $\mathrm{Pa}$ ). The column temperature was maintained at $180^{\circ} \mathrm{C}$, and the helium flow rate was $30 \mathrm{ml} / \mathrm{min}$. Identification of fatty acids was achieved by comparing the unknown peaks with results of previously run standards stored in the gas chromatograph-mass spectrometer memory. This method was also used for quantitation.

Endotoxin activity was assayed with Limulus amoebocyte lysate (LAL; Microbiological Associates, Bethesda, Md.) according to the manufacturer's recommendations.

Electron microscopy. $H$. vaginalis ATCC 14018 was grown on vaginalis agar (15) for $24 \mathrm{~h}$ at $35^{\circ} \mathrm{C}$ in a humidified incubator with $5 \% \mathrm{CO}_{2}$. Cells were harvested and fixed in cacodylate-buffered $3 \%$ glutaraldehyde. They were then postfixed with $1 \%$ buffered osmic acid for $\mathbf{4 5} \mathrm{min}$, dehydrated, and embedded in Spurr low viscosity resin. Sections were cut on an ultramicrotome (LKB Instruments, Rockville, Md.), stained with lead citrate, and examined with either a JEOL 100B or Philips 200 electron microscope.

Deoxyribonucleic acid (DNA) isolation and purification. The bacterial strains used for DNA hybridizations are listed in Table 2. DNA was extracted from 24-h-old cells grown in the broth described above. The DNA extraction method was a modification of the procedure described by Marmur (22). Briefly, 2 to $3 \mathrm{~g}$ (wet weight) of packed cells was suspended in 25 $\mathrm{ml}$ of $0.15 \mathrm{M} \mathrm{NaCl}$ plus $0.1 \mathrm{M}$ ethylenediaminetetraacetate, $\mathrm{pH} 8$. One milliliter of a $25 \%$ solution of sodium dodecyl sulfate and 2 to $4 \mathrm{mg}$ of pronase (nuclease-free; Calbiochem, La Jolla, Calif.) were added to the cell suspension, and this mixture was incubated overnight to effect cell lysis (1). H. vaginalis cells were refractory to lysis by this procedure but were lysed with 2 to $4 \mathrm{mg}$ of Protonase K (Beckman Instruments, Inc., Fullerton, Calif.) in place of pronase. The isolated DNA was repeatedly deproteinized in chloroform-isoamyl alcohol (24:1, vol/vol) and treated with ribonuclease (Calbiochem) at least twice during extraction. The concentration of extracted DNA was determined spectrophotometrically in a Beckman model 22 spectrophotometer. Isolated DNA was stored at $4^{\circ} \mathrm{C}$ over an excess of chloroform.

Determination of guanine plus cytosine $(\mathrm{G}+\mathrm{C})$ content of DNA. The G+C contents of the DNAs from CDC DF-1 and H. vaginalis ATCC 14018 and 37369 were determined by cesium chloride density gradient centrifugation in a Beckman model $\mathrm{E}$ ultracentrifuge. The method was that of Schildkraut et al. (32), and Micrococcos lysodeikticus DNA (Calbiochem) was used as a reference. The $\mathrm{G}+\mathrm{C}$ values of the other strains used in the DNA hybridizations were obtained from Bergey's Manual of Determinative Bacteriology (2).

Preparation of radioactive DNA. Radioactive DNA was produced in $H$. vaginalis ATCC 14018 by growing cells for $24 \mathrm{~h}$ in $500 \mathrm{ml}$ of low-phosphate labeling medium with $1.5 \mathrm{mCi}$ of ${ }^{32} \mathrm{P}\left(\mathrm{H}_{3}{ }^{3{ }^{32}} \mathrm{PO}_{4}\right.$, carrierfree; ICN Nutritional Biochemicals, Cleveland, Ohio). Low-phosphate labeling medium was prepared from the broth described above. The $\mathrm{pH}$ was adjusted to 10 with $40 \% \mathrm{NaOH}$, and $1 \mathrm{ml}$ of $1 \mathrm{M} \mathrm{MgCl}_{2}$ was added to 
TABLE 1. List of $H$. vaginalis strains used in this study

\begin{tabular}{|c|c|c|}
\hline Received as & Strain & Source \\
\hline H. vaginalis & BSC T4 & (1) \\
\hline H. vaginalis & BSC T7 & (1) \\
\hline H. vaginalis & $9760-2-73$ & (2) \\
\hline H. vaginalis & V7644 & (3) \\
\hline H. vaginalis & V7854 & (3) \\
\hline H. vaginalis & V8094 & (3) \\
\hline H. vaginalis & V8821 & (3) \\
\hline H. vaginalis & V9477 & (3) \\
\hline H. vaginalis & V9660 & (3) \\
\hline H. vaginalis & CV 165 & (4) \\
\hline H. vaginalis & CV 208 & (4) \\
\hline H. vaginalis & CV $3-7$ & (4) \\
\hline H. vaginalis & $\begin{array}{rrr}\text { ATCC } & 14018 \quad \text { (CV } \\
594) & & \end{array}$ & (4) \\
\hline Original isolate & M 3 & (5) \\
\hline Original isolate & M $15 \mathrm{Re}$ & (5) \\
\hline Original isolate & M 17 & (5) \\
\hline Original isolate & M 36 & (5) \\
\hline Original isolate & M 42 & (5) \\
\hline Original isolate & M 43 & (5) \\
\hline Original isolate & M 46 & (5) \\
\hline Original isolate & M 50 & (5) \\
\hline Original isolate & M 55 & (5) \\
\hline Original isolate & M 60 & (5) \\
\hline Original isolate & M 69 & (5) \\
\hline Original isolate & M 70 & (5) \\
\hline Original isolate & M 71 & (5) \\
\hline Original isolate & M 86 & (5) \\
\hline Original isolate & M 89 & (5) \\
\hline Original isolate & M 93 & (5) \\
\hline Original isolate & M 101 & (5) \\
\hline Original isolate & M 106 & (5) \\
\hline Original isolate & M 107 & (5) \\
\hline Original isolate & M 108 & (5) \\
\hline Original isolate & M 111 & (5) \\
\hline Original isolate & M 152 & (5) \\
\hline Original isolate & M 154 & (5) \\
\hline Original isolate & M 159 & (5) \\
\hline Original isolate & M 161 & (5) \\
\hline Original isolate & M 169 & (5) \\
\hline Original isolate & M 170 & (5) \\
\hline Original isolate & M 174 & (5) \\
\hline Original isolate & M 177 & (5) \\
\hline Original isolate & M 194 & (5) \\
\hline Original isolate & M 201 & (5) \\
\hline Original isolate & M 204 & (5) \\
\hline Original isolate & M 206 & (5) \\
\hline Original isolate & M 210 & (5) \\
\hline Original isolate & M 214 & (5) \\
\hline Original isolate & M 217 & (5) \\
\hline Original isolate & M 218 & (5) \\
\hline Original isolate & M 219 & (5) \\
\hline Original isolate & M 225 & (5) \\
\hline
\end{tabular}

" (1) B. S. Criswell, Baylor Medical College, Houston, Tex.; (2) California State Department of Health, Berkeley; (3) L. V. Holdeman, Virginia Polytechnic Institute, Blacksburg; (4) K.-H. Wong, Center for Disease Control, Atlanta, Ga.; (5) California State University, Northridge; (6) Microbiology Laboratories, University of California, Los Angeles.
Table 1 (Continued)

\begin{tabular}{|c|c|c|}
\hline Received as & strain & Source $^{\prime \prime}$ \\
\hline Original isolate & M 226 & (5) \\
\hline Original isolate & 23621 & (6) \\
\hline Original isolate & 35353 & (6) \\
\hline Original isolate & 35621 & (6) \\
\hline Original isolate & 36512 & (6) \\
\hline Original isolate & 36513 & (6) \\
\hline Original isolate & 36669 & (6) \\
\hline Original isolate & 36672 & (6) \\
\hline Original isolate & 36802 & (6) \\
\hline Original isolate & 37367 & (6) \\
\hline Original isolate & 37369 & (6) \\
\hline Original isolate & 37531 & (6) \\
\hline Original isolate & 39141 & (6) \\
\hline Original isolate & 38264 & (6) \\
\hline Original isolate & 38355 & (6) \\
\hline Original isolate & 38494 & (6) \\
\hline Original isolate & 38525 & (6) \\
\hline Original isolate & 38581 & (6) \\
\hline Original isolate & 30967 & (6) \\
\hline Original isolate & 41261 & (6) \\
\hline Original isolate & 43207 & (6) \\
\hline Original isolate & 43307 & (6) \\
\hline Original isolate & 43215 & (6) \\
\hline Original isolate & 43321 & (6) \\
\hline Original isolate & 54266 & (6) \\
\hline Original isolate & 54267 & (6) \\
\hline
\end{tabular}

TABLE 2. Source of organisms used in DNA hybridizations

\begin{tabular}{ll}
\hline \multicolumn{1}{c}{ Organism } & Received from" \\
\hline Haemophilus vaginalis & \\
ATCC 14018 & CDC \\
37369 & UCCL \\
CDC DF-1 ${ }^{b}$ & OVMC \\
Pasteurella multocida & UCLA \\
Haemophilus aphrophilus & WVAH \\
H. paraphrophilus & WVAH \\
H. influenzae & UCCL \\
H. parainfluenzae & UCCL \\
Streptococcus pneumoniae & UCCL \\
\hline
\end{tabular}

"Abbreviations: CDC, Center for Disease Control, Atlanta, Ga.; OVMC, Olive View Medical Center, Sylmar, Calif.; UCLA, Microbiology Department, University of California, Los Angeles; UCCL, Microbiology Laboratories, University of California, Los Angeles, Hospital and Clinics, Los Angeles; WVAH, Wadsworth Veterans Administraíion Hospital, Los Angeles, Calif.

${ }^{b}$ CDC DF-1 has been identified as a member of Bacteroides ochraceus or Capnocytophaga sp. (26).

each $150 \mathrm{ml}$ of broth. The solution was stirred for 30 min at room temperature. The resultant suspension was centrifuged at $13,000 \times g$ at $4^{\circ} \mathrm{C}$ for $20 \mathrm{~min}$. The supernatant was removed, adjusted to $\mathrm{pH} 7.3$ with concentrated $\mathrm{HCl}$, and autoclaved. DNA labeled by this procedure was extracted and purified as outlined above.

DNA-DNA hybridizations. DNA hybridizations were performed on nitrocellulose filters in $50 \%$ form- 
amide- $2 \times \mathrm{SSC}(0.15 \mathrm{M} \mathrm{NaCl}$ plus $0.015 \mathrm{M}$ trisodium citrate, $\mathrm{pH}$ 7.0) according to Kourilsky et al. (18). Microfilters (6-mm diameter) were punched out of HAWP membrane filters (Millipore Corp., Bedford, Mass.), numbered with a soft-lead pencil, and soaked overnight at $6 \times \mathrm{SSC}$. The filters were placed in a vacuum manifold with a 5-mm-diameter opening. Heat-denatured DNA $\left(100^{\circ} \mathrm{C}\right.$ for $10 \mathrm{~min}$ in dilute SSC) in $6 \times \mathrm{SSC}$ was slowly passed through the filter. Each microfilter was loaded with $1 \mu \mathrm{g}$ of DNA (18). The DNA-coated filters were dried overnight and heated for $2 \mathrm{~h}$ at $80^{\circ} \mathrm{C}$ in a vacuum desiccator. Solutions of radioactively labeled DNA were sheared (1) for $1 \mathrm{~min}$ at $40 \%$ power in a sonicator with microprobe (Ultrasonics Inc., Plainview, N.Y.) and denatured as above. For each hybridization, one DNA-coated filter was added to a $10 \times 75-\mathrm{mm}$ test tube containing $0.2 \mathrm{ml}$ of $50 \%$ formamide $-6 \times$ SSC. One microliter of radioactive DNA was added; the tube was then overlayed with a drop of mineral oil and incubated for $20 \mathrm{~h}$ at $35^{\circ} \mathrm{C}$. Blank filters were also processed in a similar manner as a control of nonspecific binding of labeled DNA to filters. After incubation, the filters were washed (18), dried at $100^{\circ} \mathrm{C}$ for $3 \mathrm{~h}$, and counted in a Beckman model LS 3133 P liquid scintillation counter. Each hybridization was done in triplicate.

\section{RESULTS}

The strains of $H$. vaginalis used in the numerical taxonomy section of this study grouped in one tight cluster (Fig. 1). This cluster had a similarity value of $95 \%$. The amount of experimental error in this numerical analysis was approximately $2 \%$, as the two identical strains, designated by different code numbers, matched at $98 \%$. It should also be noted that the type strain, $H$. vaginalis ATCC 14018, although highly related to the other organisms, is relatively far from the centrostrain, strain 37369 . No discernible biovars were found within this highly related group of strains.

Figure 2 shows the results of the fatty acid analysis of a hot phenol-water extract of $H$. vaginalis ATCC 14018. The major fatty acids and their percentage of the total are laurate $(5 \%)$, myristate $(67 \%)$, stearate $(7 \%)$, and oleate $(21 \%)$. No hydroxy fatty acids were detected with trimethylsilylation. It is important to note that the destructive method of methylation used for fatty acid analysis would not allow the detection of cyclopropane-ring-containing fatty acids. Also, 2-keto-3-deoxyoctonate was not detected in this material with periodate-thiobarbiturate reagent.

Table 3 shows the results of endotoxin analysis with LAL. The hot phenol-water extract caused gelation (positive test) of LAL at a concentration of $2 \mathrm{ng} / \mathrm{ml}$ although the system was able to detect Escherichia coli O111:B4 endotoxin at a lower level, $1 \mathrm{ng} / \mathrm{ml}$. Gelation of LAL was not noted with $H$. vaginalis extracts tested at this level.

Table 4 lists the $\mathrm{G}+\mathrm{C}$ contents of the DNAs as determined by cesium chloride density gradient centrifugation. The two $H$. vaginalis strains, ATCC 14018 and 37369, had virtually the same G+C content: $43 \pm 0.3 \mathrm{~mol} \%$. CDC DF-1 had a lower G+C content: $40.1 \pm 0.2 \mathrm{~mol} \%$.

Table 5 lists the results of the DNA hybridizations. Only $H$. : aginalis strains showed a genetic relationship to labeled ATCC 14018. $H$. vaginalis strain 37369 was related to ATCC 14018 at a level of $75 \%$. All other organisms used in the hybridizations showed no binding with labeled DNA. Nonspecific binding of labeled DNA to blank filters was approximately $0.5 \%$ of the counts obtained in the homologous system of $H$. vaginalis ATCC 14018. Also listed in this table is the standard error of the mean for the triplicate hybridizations.

Figure $3 \mathrm{~A}$ and $\mathrm{B}$ are thin-section electron micrographs of $H$. vaginalis ATCC 14018. Analysis of these micrographs reveals a cell wall with

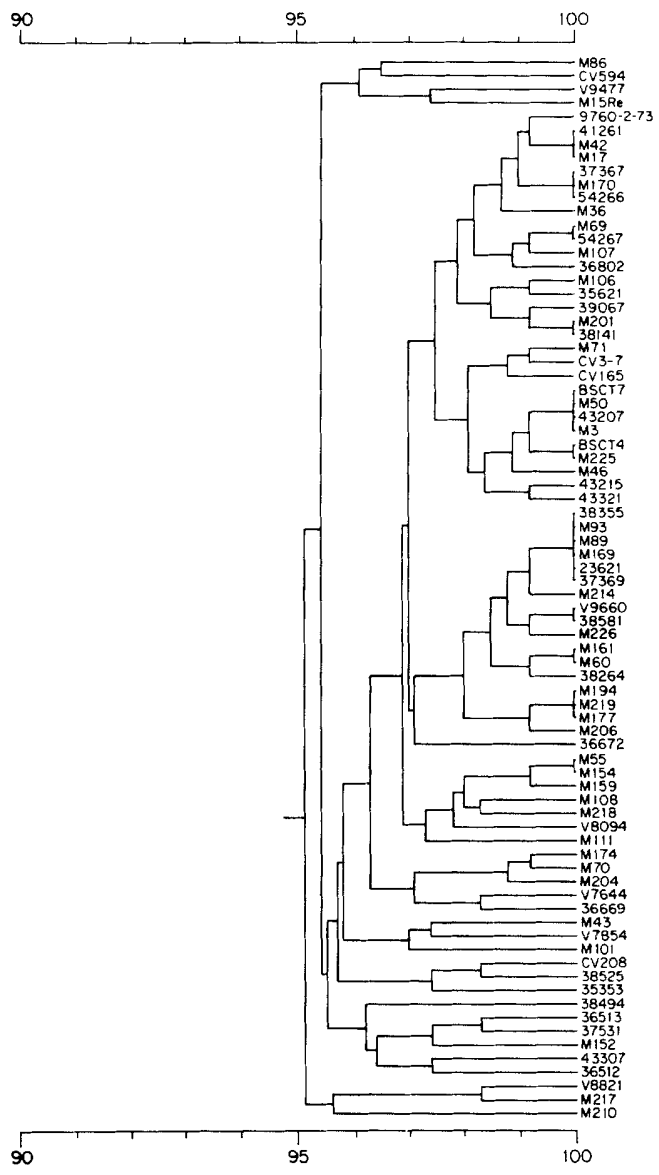

Fig. 1. Dendrogram of strains of G. vaginalis. 


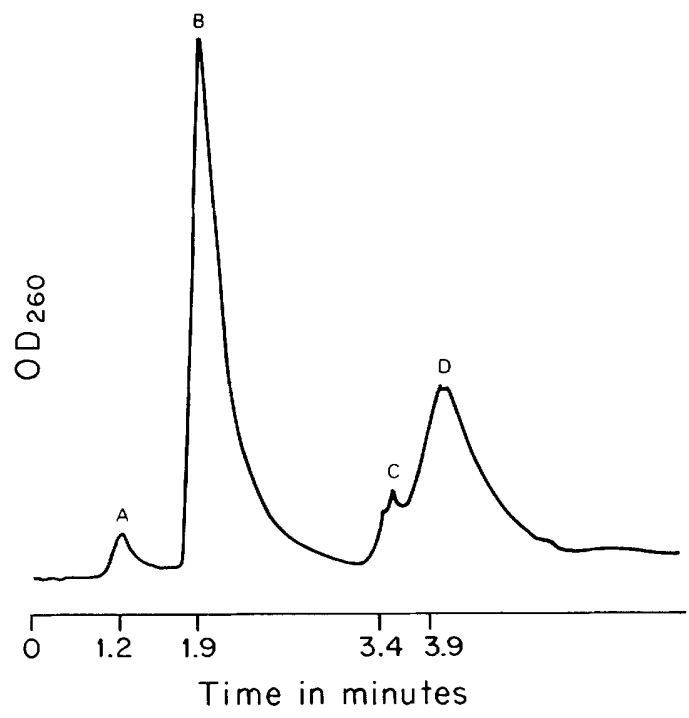

Fig. 2. Gas-liquid chromatogram of hot phenolwater extract of H. vaginalis ATCC 14018. A, laurate; $B$, myristate; $C$, stearate; $D$, oleate.

TABLE 3. Results of LAL assay with hot phenolwater extract of $H$. vaginalis ATCC 14018

\begin{tabular}{lc}
\hline \multicolumn{1}{c}{ Test sample } & $\begin{array}{c}\text { Gelation } \\
\text { (positive test) }\end{array}$ \\
\hline Positive control $^{\prime \prime}$ & + \\
Negative control $^{b}$ & - \\
Inhibition control $^{c}$ & + \\
$H$. vaginalis extract $(5 \mathrm{ng} / \mathrm{ml})$ & + \\
$H$. vaginalis extract $(2.5 \mathrm{ng} /$ & + \\
ml) & - \\
$H$. vaginalis extract $(1 \mathrm{ng} / \mathrm{ml})$ &
\end{tabular}

\footnotetext{
"Positive control, E. coli O111:B4 endotoxin in concentration of $1 \mathrm{ng} / \mathrm{ml}$ plus LAL.

${ }^{b}$ Negative control, pyrogen-free water plus LAL.

'Inhibition control, E. coli O111:B4 endotoxin plus LAL.
}

TABLE 4. $G+C$ content of DNA samples as determined by cesium chloride density gradient centrifugation

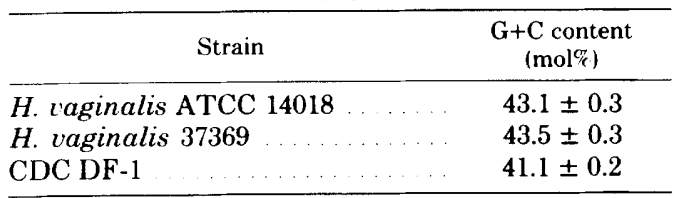

multiple laminations. The laminations consist of two 5-nm-thick, electron-dense layers separated 5 -nm-thick, electron-translucent layers. Overall thickness of the wall is approximately $20 \mathrm{~nm}$. On the exterior of the wall is a flocculent layer approximately 5 to $10 \mathrm{~nm}$ thick.
TABLE 5. Relative binding ratios of DNA from $H$. vaginalis ATCC 14018

\begin{tabular}{lrr}
\hline \multicolumn{1}{c}{ Organism } & $\mathrm{RBR}^{\prime}$ & SEM $^{h}$ \\
\hline H. vaginalis ATCC 14018 & 100 & 2.65 \\
H. vaginalis 37369 & 75 & 6.44 \\
CDC DF-1 & 0 & 2.68 \\
Pasteurella multocida UCLA & 0 & 5.42 \\
Streptococcus pneumoniae & 0 & 8.48 \\
$\quad$ UCCL & & \\
Haemophilus influenzae & 0 & 10.10 \\
$\quad$ UCCL & & \\
H. aphrophilus WVAH & 0 & 3.40 \\
H. paraphrophilus WVAH & 0 & 2.55 \\
H. parainfluenzae UCCL & 0 & 1.78 \\
\hline
\end{tabular}

"RBR, Relative binding ratio.

${ }^{b}$ SEM, Standard error of the mean calculated from triplicate samples.

\section{DISCUSSION}

Haemophilus vaginalis is presently listed as a species incertae sedis in Bergey's Manual of Determinative Bacteriology (2). Because a genus compatible with features of this organism has not been suggested heretofore, $H$. vaginalis remains a taxonomic orphan. This classification failure has been caused primarily by lack of agreement on the fine structure of the $H$. vaginalis cell wall.

Reyn et al. (29) reported that the microscopic morphology of $H$. vaginalis, particularly of the cell walls and septa, more closely resembled that of a gram-positive organism. Although interpretation of the cell wall fine structure in their micrographs is difficult (6), the presence of septa and mesosomes is obvious. Whereas earlier workers placed taxonomic significance on this type of septum formation in gram-positive bacteria (25), more recent work has shown that Escherichia coli and other gram-negative organisms also form septa in this manner (3). Additionally, E. coli has been shown to form mesosomes morphologically similar to those in the micrographs of Reyn et al. (29).

In contrast to the view of Reyn et al., Criswell and associates $(6,7)$ published micrographs of $H$. vaginalis cell walls which, in their opinion, depict a fine structure more typical of a grampositive organism. Although an outer membrane as demonstrated by Salton (31) is not readily apparent, the $H$. vaginalis cell walls in these micrographs do show multiple layers. Although in neither our micrographs nor those of Criswell et al. does the cell wall morphology of $H$. vaginalis appear like that of a "typical" gram-negative organism, e.g., E. coli, the wall does more closely resemble that of a gram-negative than a grampositive organism. 

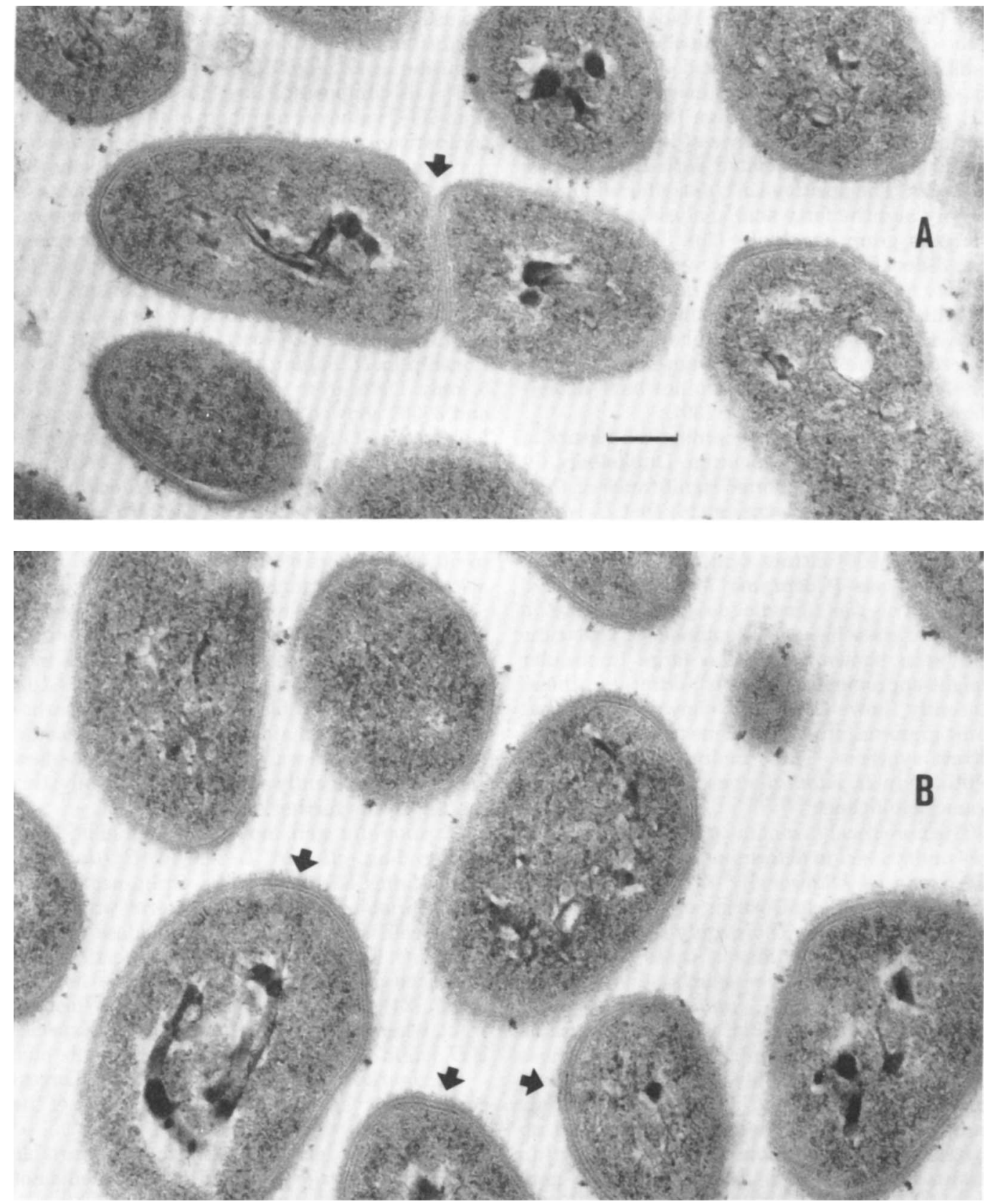

Fig. 3. Cross sections of Gardnerella vaginalis ATCC 14018. (A) Arrow points to area of cross wall formation showing multiple laminations; $(B)$ multilaminated cell walls consisting of two 5 - $n$ m-thick, electrondense layers separated by 5-nm-thick, electron-translucent layers. The overall thickness of the wall is approximately $20 \mathrm{~nm}$. The bar in (A) represents $50 \mathrm{~nm}$.

In addition to the micrographic evidence, the view that $H$. vaginalis is a gram-negative organism is also supported by chemical analysis of the cell wall.
Vickerstaff and Cole (34) and Criswell et al. (6) reported biochemical analyses of $H$. vaginalis cell walls. Both groups found numerous amino acids in these walls. Additionally, Criswell 
et al. found that mucopeptide made up only $20 \%$ of the total cell wall weight and also that the cell walls contained no teichoic acid. These features are compatible with a gram-negative cell wall (31). We have extended these findings by presenting data on the presence of lipopolysaccharide-like fraction associated with $H$. vaginalis cell walls. The positive LAL assay for endotoxin activity and the fatty acid analysis are compatible with gram negativity (30). The lack of 2keto-3-deoxyoctonate in this material in no way reflects on the lipopolysaccharide nature of this hot phenol-water extract. While 2-keto-3-deoxyoctonate is present in all members of the family Enterobacteriaceae, other gram-negative bacteria, e.g., Vibrio cholerae, do not have detectable levels of this substance (30).

One final argument concerning the nature of $H$. vaginalis deserves mention. Dunkelberg (9) reported on the taxonomic significance of findings by Jones and Weitzman (16) that $H$. vaginalis has a "small" (molecular weight approximately 100,000 ) citrate synthase (citrate oxaloacetate-lyase [Coenzyme A-acetylating], EC 4.1.3.7). This was considered significant, since all gram-negative bacteria examined at that time had been shown to have a large (molecular weight approximately 250,000 ) citrate synthase. Recently, however, it was shown $(4,36)$ that some gram-negative organisms also have a small citrate synthase. Thus, finding a small citrate synthase in $H$. vaginalis has little, if any, taxonomic significance.

The numerical taxonomy portion of this study was undertaken to determine possible biovars of $H$. vaginalis. Additionally, the intent was also to determine the centrostrain of a large number of isolates and more thoroughly to characterize the biochemical reactions of these strains. Because of the high degree of relatedness among strains, no biovars of $H$. vaginalis are apparent in the phenogram in Fig. 1. Indeed, variable results in the biochemical profiles of these strains were observed only in lipase and $\beta$-galactosidase production and in fermentation of six carbohydrates (14). These features showed no correlation with possible subgroupings within strains examined. It is also important to note that strains V7644, V7854, V8094, V8821, V9477, and V9660 were initially isolated as obligately anaerobic stains of $H$. vaginalis (21). These strains also showed no tendency to cluster as a biovar or subgroup. The centrostrain from numerical analysis was strain 37369 , and this organism was used for DNA hybridizations.

Early proposals of genera for $H$. vaginalis did not consider genetic relationships between this organism and members of the newly proposed genus. Because of this, genera such as Corynebacterium and Actinomyces were suggested for inclusion of $H$. vaginalis. Even if differences in cell wall composition are not considered, the high $\mathrm{G}+\mathrm{C}$ values of members of these genera, in comparison with the value for $H$. vaginalis, make a genetic relationship highly unlikely (8).

Organisms with $\mathrm{G}+\mathrm{C}$ contents in the range of 38 to $44 \mathrm{~mol} \%$ were chosen for DNA hybridizations. Additionally, the only other requirement was that they be facultatively anaerobic; no obligately aerobic or anaerobic organisms were used. Streptococcus pneumoniae was included because of a recent report of an antigenic relationship to $H$. vaginalis (33). As seen in Table 5 , only DNA from $H$. vaginalis ATCC 14018 and 37369 showed any ability to hybridize with labeled ATCC 14018. Thus, there appears to be no genetic relationship between $H$. vaginalis and members of the genera Haemophilus, Pasteurella, and Streptococcus. Haemophilus aphrophilus, an organism probably not related to other members of the genus, and CDC DF-1 also show no relationship to $H$. vaginalis.

In the absence of existing genera with genetic features compatible with those of $H$. vaginalis, we are compelled to place this organism in a new genus. This genus should be restricted to facultatively anaerobic bacteria that use carbohydrates as their major energy source. Because of the unusual cell wall of this organism, the new genus is not presently assignable to a family; this matter awaits further study.

Gardnerella gen. nov. (Gard.ner.el'la. M.L. dim. ending -ella; M. L. fem. n. Gardnerella; named after H. L. Gardner). Gram-negative to gram-variable, rod-shaped bacteria with laminated cell walls. Catalase and oxidase are not produced. Facultatively anaerobic. Acetic acid is produced as the major end product of fermentation (24). Found in the human genital/urinary tract, where it causes vaginitis. The type species is G. vaginalis (Gardner and Dukes) comb. nov.

Gardnerella vaginalis (Gardner and Dukes) comb. nov. (vag.in.al'is. L. adj. vaginalis, of the vagina).

Pleomorphic, gram-negative to gram-variable rods which average 0.5 by $1.5 \mu \mathrm{m}$. Filaments not seen. Non-encapsulated. Nonmotile.

Agar colonies: on vaginalis agar (15), colonies are 0.4 to $0.5 \mathrm{~mm}$ in diameter after a 48 -h incubation at $35^{\circ} \mathrm{C}$ in a humidified atmosphere with $5 \% \mathrm{CO}_{2}$. These colonies are round, opaque, and smooth. Colonies on Casman's agar are 0.1 to 0.2 $\mathrm{mm}$ in diameter in 24 to $48 \mathrm{~h}$ and are circular, convex, entire, and smooth (2).

Biochemical reactions: acid produced from dextrin, fructose, galactose, glucose, maltose, 
mannose, ribose, and starch. No acid from arbutin, cellobiose, inositol, mannitol, rhamnose, or sorbitol. Lactose, sucrose, and xylose are fermented with variable results (14). Oxidase- and catalase-negative. Poor growth on sheep blood agar, and no growth on MacConkey agar, Thayer-Martin agar, or $0.01 \%$ tellurite agar (14). Nitrates not reduced. Indole- and urease-negative.

Oxygen requirements: facultatively anaerobic.

Temperature requirements: optimum, 35 to $37^{\circ} \mathrm{C}$; growth occurs at 25 and $42^{\circ} \mathrm{C}(14)$.

$\mathrm{pH}$ requirements: optimum $\mathrm{pH}, 6$ to 6.5 ; no growth occurs at $\mathrm{pH} 4.0$ and slight growth occurs at $\mathrm{pH} 4.5(2)$.

Hemolysis: beta-hemolytic on human and rabbit blood agars. No hemolysis on sheep blood agar.

Nutrition: fastidious in its growth requirements but does not need nicotinamide adenine dinucleotide ( $\mathrm{V}$ factor), hemin ( $\mathrm{X}$ factor), or coenzyme-like substances $(10,11)$. Reported to require biotin, folic acid, niacin, thiamine, riboflavin, and two or more purines-pyrimidines (10). Fermentative, with acetic acid the major end product (24). Fermentable carbohydrates improve growth (10).

Antigenic structure: there are seven serological groups by precipitin tests (11).

Pathogenicity: major cause of bacterial "nonspecific" vaginitis $(13,27)$.

Source: isolated from the human genital/urinary tract. Worldwide distribution.

DNA base composition: $43 \pm 1 \mathrm{~mol} \% \mathrm{G}+\mathrm{C}$.

Type strain: 594 of Gardner and Dukes (= ATCC $14018=$ NCTC 10287) (20).

\section{ACKNOWLEDGMENTS}

This research was supported in part by a grant from Squibb Pharmaceuticals.

We are indebted to Dennis Tso for his excellent technical assistance during this study.

\section{REPRINT REQUESTS}

Address reprint requests to: Dr. J. R. Greenwood, Public Health Laboratory, County of Orange, P.O. Box 355, Santa Ana, CA 92702.

\section{LITERATURE CITED}

1. Brenner, D. J., G. R. Fanning, A. V. Rake, and K. E. Johnson. 1969. Batch procedure for thermal elution of DNA from hydroxyapatite. Anal. Biochem. 28:447-459.

2. Buchanan, R. E., and N. E. Gibbons (ed.). 1974. Bergey's manual of determinative bacteriology, 8 th ed. The Williams \& Wilkins Co., Baltimore.

3. Burdett, I. D. J., and R. G. E. Murray. 1974. Electron microscope study of septum formation in Escherichia coli strains $\mathrm{B}$ and $\mathrm{B} / \mathrm{r}$ during synchronous growth. J. Bacteriol. 119:1039-1056.

4. Cazzulo, J. J. 1973. On the regulatory properties of a halophilic citrate synthase. FEBS Lett. 30:339-342.

5. Criswell, B. S., C. L. Ladwig, H. L. Gardner, and C.
D. Dukes. 1969. Haemophilus vaginalis: vaginitis by inoculation from culture. Obstet. Gynecol. 33:195-199.

6. Criswell, B. S., J. H. Marston, W. A. Stenback, S. H. Black, and H. L. Gardner. 1971. Haemophilus vaginalis 594, a gram-negative organism? Can. J. Microbiol. 17:865-869.

7. Criswell, B. S., W. A. Stenback, S. H. Black, and H. L. Gardner. 1972. Fine structure of Haemophilus vaginalis. J. Bacteriol. 109:930-932.

8. De Ley, J., and J. Van Muylem. 1963. Some applications of deoxyribonucleic acid base composition in bacterial taxonomy. Antonie van Leeuwenhoek J. Microbiol. Serol. 29:344-358.

9. Dunkelberg, W. E. 1974. Monograph: a bibliographic review of Corynebacterium vaginale ( $H$. vaginalis). Atlanta Printing Office, Fort McPherson, Ga.

10. Dunkelberg, W. E., Jr., and I. McVeigh. 1969. Growth requirements of Haemophilus vaginalis. Antonie van Leeuwenhoek J. Microbiol. Serol. 35:129-145.

11. Edmunds, P. N. 1962. The biochemical, serological and haemagglutinating reactions of "Haemophilus vaginalis." J. Pathol. Bacteriol. 83:411-422.

12. Frampton, J., and Y. Lee. 1964. Is Haemophilus vaginalis a pathogen in the female genital tract? J. Obstet. Gynaecol. Br. Commonw. 71:436-442.

13. Gardner, H. L., and C. D. Dukes. 1955. Haemophilus vaginalis vaginitis. A newly defined specific infection previously classified "nonspecific" vaginitis. Am. J. Obstet. Gynecol. 69:962-976.

14. Greenwood, J. R., and M. J. Pickett. 1979. Salient features of Haemophilus vaginalis. J. Clin. Microbiol. 9:200-204.

15. Greenwood, J. R., M. J. Pickett, W. J. Martin, and E. G. Mack. 1977. Haemophilus vaginalis (Corynebacterium vaginale): method for isolation and rapid biochemical identification. Health Lab. Sci. 14: 102-106.

16. Jones, D., and P. D. J. Weitzman. 1971. Taxonomic significance of citrate synthase. J. Gen. Microbiol. 69: xi.

17. Josey, W. E., and D. W. Lambe, Jr. 1976. Epidemiologic characteristics of women infected with Corynebacterium vaginale (Haemophilus vaginalis). J. Am. Vener. Dis. Assoc. 3:9-13.

18. Kourilsky, P., J. Leidner, and G. Y. Tremblay. 1971. DNA-DNA hybridization of filters at low temperature in the presence of formamide or urea. Biochimie 53: 1111-1114.

19. Leopold, S. 1953. Heretofore undescribed organism isolated from the genitourinary system. U.S. Armed Forces Med. J. 4:263-266.

20. Lessel, E. F. 1962. Bacterial type cultures of the American Type Culture Collection. I. Int. Bull. Bacteriol. Nomencl. Taxon. 12:71-88.

21. Malone, B. H., M. Schreiber, N. J. Schneider, and L. V. Holdeman. 1975. Obligately anaerobic strains of Corynebacterium vaginale (Haemophilus vaginalis). J. Clin. Microbiol. 2:272-275.

22. Marmur, J. 1961. A procedure for isolation of deoxyribonucleic acid from micro-organisms. J. Mol. Biol. 3: 208-218.

23. Morrison, W. R., and L. M. Smith. 1964. Preparation of fatty acid methyl esters and dimethylacetals from lipids with boron fluoride-methanol. J. Lipid Res. 5:600-608.

24. Moss, C. W., and W. E. Dunkelberg, Jr. 1969. Volatile and cellular fatty acids of Haemophilus vaginalis. J. Bacteriol. 100:544-546.

25. Murray, R. G. E. 1962 . Fine structure and taxonomy of bacteria, p. 119-144. In G. C. Ainsworth and P. H. A. Sneath (ed.), Microbial classification. Twelfth Symposium of the Society for General Microbiology. University Press, Cambridge.

26. Newman, M. G., V. L. Sutter, M. J. Pickett, U. Blach- 
man, J. R. Greenwood, V. Grinenko, and D. Citron. 1979. Detection, identification, and comparison of Capnocytophaga, Bacteroides ochraceus, and DF-1. J. Clin. Microbiol. 10:557-562.

27. Pheifer, T. A., P. S. Forsyth, M. A. Durfee, H. M. Pollock, and K. K. Holmes. 1978. Nonspecific vaginitis. Role of Haemophilus vaginalis and treatment with metronidazole. N. Engl. J. Med. 298:1429-1434.

28. Pontefract, R. D., G. Bergeron, and F. S. Thatcher. 1969. Mesosomes in Escherichia coli. J. Bacteriol. 97: 367-375.

29. Reyn, A., A. Birch-Andersen, and S. P. Lapage. 1966. An electron microscope study of thin sections of Hae. mophilus vaginalis (Gardner and Dukes) and some possibly related species. Can. J. Microbiol. 12:11251136.

30. Rietschel, E. Th., H. Gottert, O. Luderitz, and O. Westphal. 1972. Nature and linkages of the fatty acids present in the lipid-A component of Salmonella lipopolysaccharides. Eur. J. Biochem. 28:166-173.

31. Salton, M. R. J. 1964. The bacterial cell wall, p. 1-293. American Elsevier Publishing Co., Inc., New York.

32. Schildkraut, C. L., J. Marmur, and P. Doty. 1962. Determination of the base composition of deoxyribo- nucleic acid from its buoyant density in $\mathrm{CsCl}$. J. Mol Biol. 4:430-443.

33. Smaron, M. F., and J. L. Vice. 1977. Immunological and chemical characterization of the extracellular antigens from Corynebacterium vaginale. Infect. Immun. 18: 356-362.

34. Vickerstaff, J. M., and B. C. Cole. 1969. Characterization of Haemophilus vaginalis, Corynebacterium cervicis, and related bacteria. Can. J. Microbiol. 15:587594.

35. Weissbach, A., and J. Hurwitz. 1959. The formation of 2-keto-3-deoxyheptonic acid in extracts of Escherichia coli B. I. Identification. J. Biol. Chem. 234:705-709.

36. Weitzman, P. D. J. 1978. Anomalous citrate synthase from Thermus aquaticus. J. Gen. Microbiol. 106:383386.

37. Westphal, O., and K. Jann. 1965. Bacterial lipopolysaccharides. Extraction with phenol-water and further applications of the procedure. Methods Carbohydr. Chem. 5:83-91.

38. Zinnemann, K., and G. C. Turner. 1963. The taxonomic position of "Haemophilus vaginalis" (Corynebacte. rium vaginale). J. Pathol. Bacteriol. 85:213-219. 